\title{
Infectious disease in an era of global change
}

Rachel E. Baker(10 ${ }^{1,2 凶}$, Ayesha S. Mahmud ${ }^{3}$, Ian F. Miller $\mathbb{1}^{1,4}$, Malavika Rajeev ${ }^{1}$, Fidisoa Rasambainarivo 1,2,5, Benjamin L. Rice, ${ }^{1,6}$, Saki Takahashi ${ }^{7}$, Andrew J. Tatem ${ }^{8}$, Caroline E. Wagner ${ }^{9}$, Lin-Fa Wang ${ }^{10}{ }^{10,11}$, Amy Wesolowski12 and C. Jessica E. Metcalf ${ }^{1,13 凶}$

Abstract | The twenty-first century has witnessed a wave of severe infectious disease outbreaks, not least the COVID-19 pandemic, which has had a devastating impact on lives and livelihoods around the globe. The 2003 severe acute respiratory syndrome coronavirus outbreak, the 2009 swine flu pandemic, the 2012 Middle East respiratory syndrome coronavirus outbreak, the 2013-2016 Ebola virus disease epidemic in West Africa and the 2015 Zika virus disease epidemic all resulted in substantial morbidity and mortality while spreading across borders to infect people in multiple countries. At the same time, the past few decades have ushered in an unprecedented era of technological, demographic and climatic change: airline flights have doubled since 2000, since 2007 more people live in urban areas than rural areas, population numbers continue to climb and climate change presents an escalating threat to society. In this Review, we consider the extent to which these recent global changes have increased the risk of infectious disease outbreaks, even as improved sanitation and access to health care have resulted in considerable progress worldwide.

In premodern times, colonization, slavery and war led to the global spread of infectious diseases, with devastating consequences (FIG. 1a). Human diseases such as tuberculosis, polio, smallpox and diphtheria circulated widely, and before the advent of vaccines, these diseases caused substantial morbidity and mortality. At the same time, animal diseases such as rinderpest spread along trade routes and with travelling armies, with devastating impacts on livestock and dependent human populations ${ }^{1}$. However, in the past two decades, medical advances, access to health care and improved sanitation have reduced the overall mortality and morbidity linked to infectious diseases, particularly for lower respiratory tract infections and diarrhoeal disease (FIG. $1 \mathrm{~d}$ ). The swift development of the severe acute respiratory syndrome coronavirus 2 (SARS-CoV-2) vaccine speaks to the efficacy of modern science in rapidly countering threats from emerging pathogens. Nevertheless, infectious disease burden remains substantial in countries with low and lower-middle incomes, while mortality and morbidity associated with neglected tropical diseases, HIV infection, tuberculosis and malaria remain high. Moreover, deaths from emerging and re-emerging infections, in comparison with seasonal and endemic infections, have persisted throughout the twenty-first century (FIG. 1c). This points to a possible new era of infectious disease, defined by outbreaks of emerging, re-emerging and endemic pathogens that spread quickly, aided by global connectivity and shifted ranges owing to climate change (FIG. 1d).

Here, we review how recent anthropogenic climatic, demographic and technological changes have altered the landscape of infectious disease risk in the past two decades. In terms of climate change, we consider both the influence of recent warming and projected future changes. For demographic change, we include trends such as urbanization (FIG. 1 b), population growth, land-use change, migration, ageing and changing birth rates. For technological changes, we primarily consider advances that enable cheaper, faster global travel and trade (FIG. 1 b), as well as improved health care. We do not explicitly address economic change; however, economic changes, including economic development, are crucial drivers of these three factors: climate, demography and technology. We also do not explicitly discuss natural drivers of pathogen evolution or biological processes unless they interact with human-driven global change.

New infections chart a pathway beginning with emergence, followed by local-scale transmission, movement beyond borders and possible global-scale spread. Global changes may differentially affect the risk of emergence, the dynamics of disease within a local population and the global spread of diseases between populations. We provide an overview of each step, first considering features of recent global change that have altered the risks of spillover of viral, fungal, bacterial and apicomplexan 
(malaria) infections into human populations, then detailing how spread within human populations, driven by the seasonal dynamics of transmission, may be impacted by global change, of relevance to both emergent and established pathogens. Finally, we consider changes to the drivers of global spread, focusing in particular on travel, migration and animal and plant trade.

\section{Pathogen emergence into human populations}

Recent decades have seen repeated pathogen emergence from wild or domestic animal reservoirs into human populations, from HIV-1 and HIV-2, to the 1918 influenza virus, to Middle East respiratory syndrome coronavirus, to SARS-CoV-2 (REFS $\left.{ }^{2-4}\right)$. For a novel pathogen to become a threat to human populations, first, contact between humans and the animal reservoir must occur; the pathogen must either have or evolve (BOX 1) the capacity for human-to-human transmission ${ }^{5}$; and finally, this human-to-human transmission must enable expansion of the pathogen's geographical range beyond the zone of spillover. Recent global changes have affected each of these steps.

Patterns of contact between human and wildlife reservoirs have increased as human populations move into previously unoccupied regions. Population growth and agricultural expansion, coupled with increasing wealth and larger property sizes, are driving factors for these interactions and the resulting habitat destruction. This may occur alongside behaviours that increase the potential for spillover, such as consumption of wild meat ${ }^{6}$, or intensifying contact between wild and domestic animal hosts. For example, Nipah virus has been identified in several bat populations, particularly flying foxes, but in 1999 caused a severe disease outbreak in Malaysia, primarily among pig farmers ${ }^{7}$. It is hypothesized that the spillover of Nipah virus from bats to pigs was driven by three factors related to global change: pig farms expanding into the bat habitat; intensification of pig farming, leading to a high density of hosts; and international trade, leading to the spread of the infection among other pig populations in Malaysia and Singapore ${ }^{8}$. Expanding

\footnotetext{
Author addresses

${ }^{1}$ Department of Ecology and Evolutionary Biology, Princeton University, Princeton, NJ, USA.

2Princeton High Meadows Environmental Institute, Princeton University, Princeton, NJ, USA.

${ }^{3}$ Department of Demography, University of California, Berkeley, Berkeley, CA, USA. ${ }^{4}$ Rocky Mountain Biological Laboratory, Crested Butte, CO, USA.

${ }^{5}$ Mahaliana Labs SARL, Antananarivo, Madagascar.

${ }^{6}$ Madagascar Health and Environmental Research (MAHERY), Maroantsetra, Madagascar. ${ }^{7}$ EPPIcenter Program, Division of HIV, ID, and Global Medicine, Department of Medicine,

University of California, San Francisco, San Francisco, CA, USA.

${ }^{8}$ WorldPop, School of Geography and Environmental Science, University of Southampton, Southampton, UK.

${ }^{9}$ Department of Bioengineering, McGill University, Montreal, Quebec, Canada.

${ }^{10}$ Programme in Emerging Infectious Diseases, Duke-NUS Medical School, Singapore,

Singapore.

${ }^{11}$ Duke Global Health Institute, Duke University, Durham, NC, USA.

${ }^{12}$ Department of Epidemiology, Johns Hopkins Bloomberg School of Public Health, Johns

Hopkins University, Baltimore, MD, USA.

${ }^{13}$ Princeton School of Public and International Affairs, Princeton University, Princeton, NJ, USA.
}

Fig. 1 | Human connectivity and infectious disease outbreaks in premodern and modern times. a | Examples of epidemic periods associated with different eras of human transportation (land, maritime and air travel) are shown. Overland trade networks and war campaigns are thought to have contributed to multiple epidemics in the Mediterranean in late classical antiquity (green), beginning with the Antonine plague, which reportedly claimed the life of the Roman emperor Lucius Verus ${ }^{125-128}$. Maritime transportation (red and grey) leading to European contact with the Americas and the subsequent Atlantic slave trade resulted in the importation of Plasmodium falciparum malaria and novel viral pathogens ${ }^{129}$. In modern times, air travel (purple) resulted in the importation of severe acute respiratory syndrome (SARS) coronavirus to 27 countries before transmission was halted ${ }^{130} . \mathbf{b} \mid$ In recent years, increases in air travel, trade and urbanization at global (left) and regional (right) scales have accelerated, indicating ever more frequent transport of people and goods between growing urban areas (source World Bank). c | Log deaths from major epidemics in the twenty-first century (source World Health Organization). d | Disability-adjusted life years lost from infectious diseases (source Our World in Data). MERS, Middle East respiratory syndrome;

NTD, neglected tropical disease.

agriculture and its intensification may create conditions that favour pathogen circulation within domestic animal (or plant) reservoirs via high-density farming practices ${ }^{9}$. Beyond creating opportunities for emergence of problematic livestock pathogens, this could also increase opportunities for evolution of novel variants of risk to humans in domestic animal reservoirs. This may occur alongside increasing risk to workers interacting with animal populations ${ }^{10}$ as a result of work practices. Global increase in the demand for and resulting intensification of meat production will importantly drive these processes, and associated use of antibiotics in domestic animals has the potential to select for resistant strains of bacteria with potential to affect human health ${ }^{11}$.

The nature of human populations that are exposed to potential spillover is also changing. For example, the elimination of smallpox led to the cessation of smallpox vaccination, which may have enabled the expansion of monkeypox $^{12}$. More generally, globally ageing populations may provide an immune landscape that is more at risk of spillover, as ageing immune landscapes are less capable of containing infectious agents ${ }^{13}$. The intersection between declining function of immunity at later ages $^{14}$ and globally ageing populations may increase the probability of pathogen emergence, but this remains conjectural and an important area for research. The changing global context may allow existing human pathogens to both evolve novel characteristics and expand in scope. Selection for drug resistance now occurs worldwide, and antibiotic resistance has and will evolve repeatedly ${ }^{15}$. As with antibiotic resistance, rapid global spread is commonplace for antimalarial resistance following evolution ${ }^{16}$.

Climate change may play a role in the risk from pathogen spillover. Changing environmental conditions can alter species range and density, leading to novel interactions between species, and increase the risk of zoonotic emergence ${ }^{17}$. A series of compounded environmental 


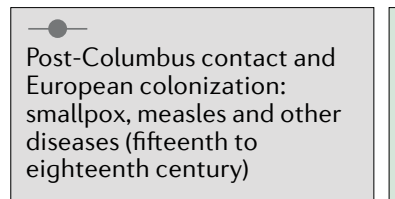

$-1$

Classical antiquity trade and war: Antonine plague (second century) Plague of Cyprian (third century) Justinian plague (sixth century)
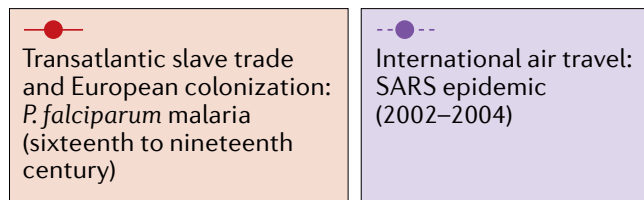

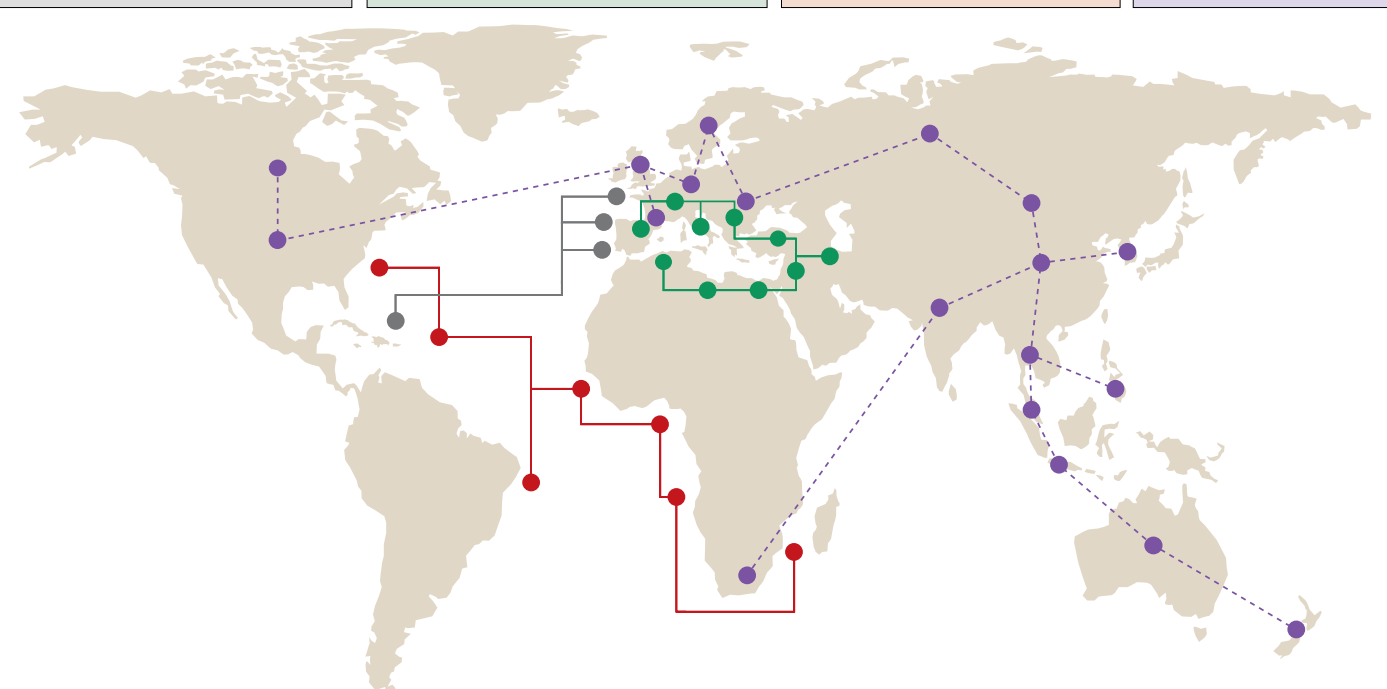

b
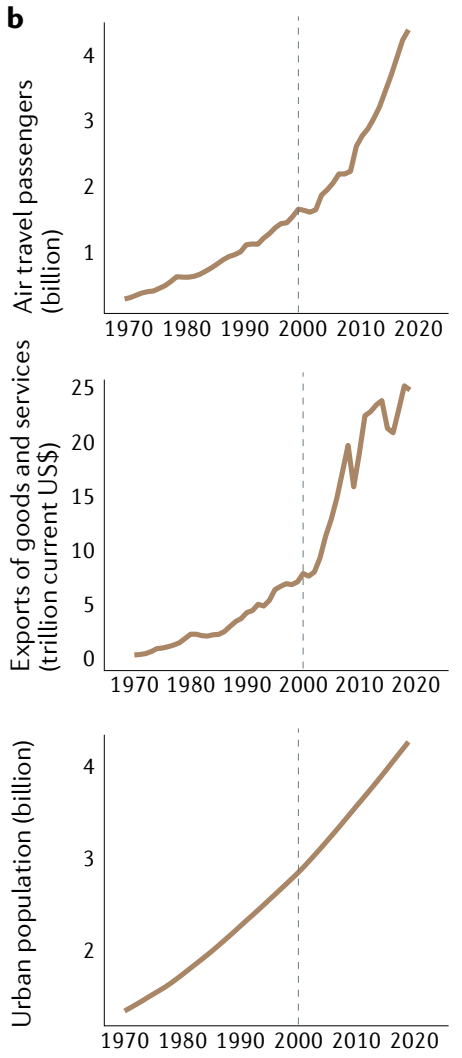
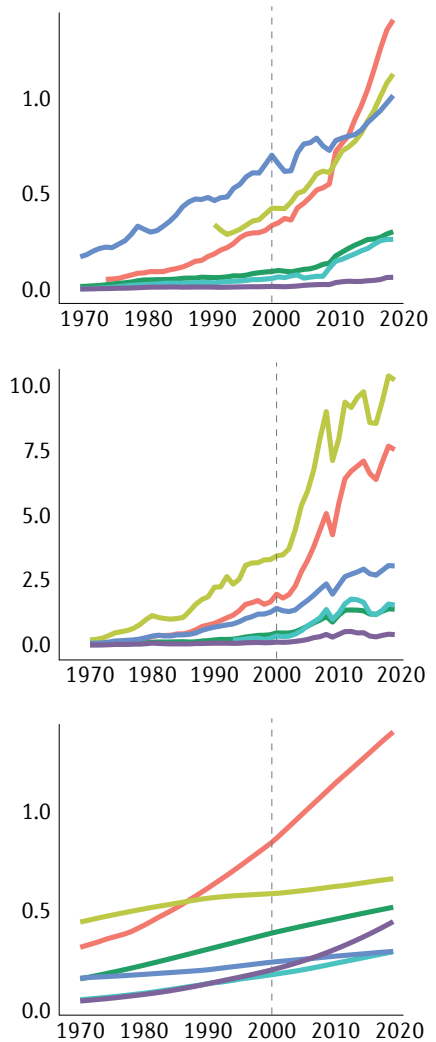

c

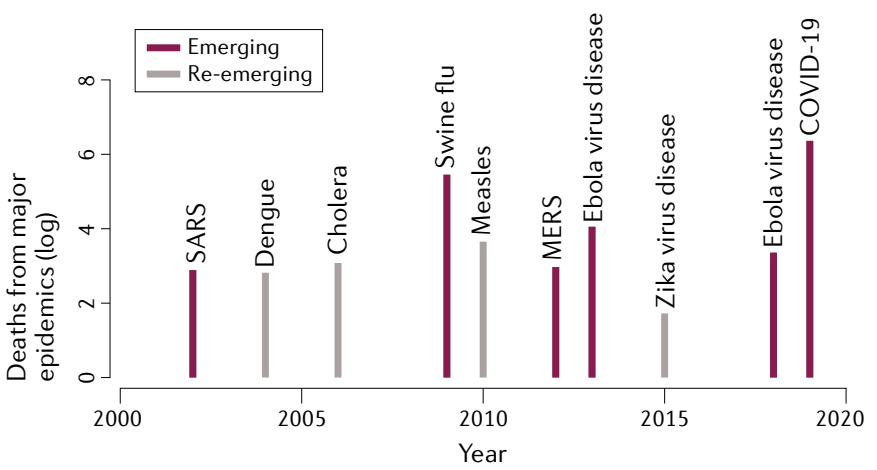

d

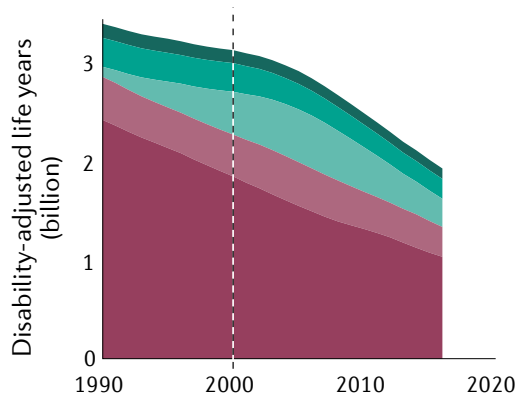

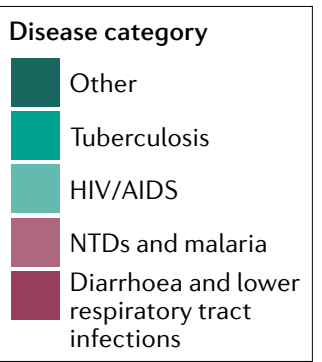

$\begin{array}{ll}\text { World } & \text { Sub-Saharan Africa } \\ \text { East Asia and Pacific } & \text { Latin America and Caribbean } \\ \text { Europe and Central Asia } & \text { North America } \\ \text { Middle East and North Africa } & \end{array}$

factors, including a long period of drought followed by extreme precipitation, is hypothesized to have driven an upsurge in rodent populations causing the emergence of pulmonary hantavirus in 1993 (REF. ${ }^{18}$ ). Similarly, evidence suggests that populations of the black flying fox in Australia, a key reservoir of Hendra virus, have moved $100 \mathrm{~km}$ southward in the past 100 years owing to climatic changes. This shifting range likely caused Hendra 
virus to spill over into southern horse populations, and these horses subsequently infected humans ${ }^{19,20}$. Patterns of change are likely occurring in other bat populations globally but remain understudied - a clear cause for concern given the crucial role bat populations play as a reservoir host for several high-fatality pathogens ${ }^{21}$.

Rapid rates of urbanization in low-income and middle-income countries, and the increase in populations residing in crowded, low-quality dwellings, have created new opportunities for the emergence of infectious diseases (FIG. 2). Urbanization has promoted the emergence and spread of arboviral diseases such as dengue, Zika virus disease and chikungunya, which are transmitted by Aedes aegypti and Aedes albopictus mosquitoes that are well adapted to urban areas ${ }^{22-24}$. Population density appears correlated with the preference of Ae. aegypti for human odour, and hence the evolution of human-biting - the transmission pathway for arboviral disease ${ }^{24}$. However the role of urbanization in vector-borne disease spread is complex: the preference of the Anopheles spp. vector for rural environments may have led to a decline in the prevalence of malaria in urbanizing regions ${ }^{25}$. Nevertheless, dense and highly

\section{Box 1 | Global change and evolution of hosts and pathogens}

Mutations constantly arise in the genomes of all species, from viruses to elephants. Some genetic changes may have no observable effects on fitness (and thus will be selectively neutral), but can be used to track pathogen spread; for example, to trace the impacts of global connectivity on an outbreak ${ }^{70}$. Some genetic changes will affect disease phenotypes, potentially increasing the transmissibility, virulence or immune escape of a pathogen lineage ${ }^{133}$. The degree to which such mutations increase in frequency or spread geographically will depend on the degree to which they increase fitness, as well as pathogen population dynamics, which may be modulated by the global change context. Increases in the density and geographical distribution of susceptible hosts (whether they be people, crops or livestock) may provide greater opportunity for novel variants to emerge ${ }^{9}$ simply by amplifying pathogen populations and thus circulating mutations. While understanding the nuance of cross-scale selection (that is, how the selective context of the individual host translates into the selective context at the scale of populations) remains a challenging frontier ${ }^{134}$, it is likely that ageing populations or the presence of immunosuppressive pathogens might further modulate selection pressures. Indeed, it has been suggested that the emergence of more transmissible or less immune-vulnerable variants of severe acute respiratory syndrome coronavirus 2 (SARS-CoV-2) was enabled in part by selection processes occurring during chronic infections in immunosuppressed individuals ${ }^{135}$. Greater global connectivity leads to more frequent exchange of this genetic material between populations of the same or different species, potentially leading to the erosion of evolved or engineered host resistance and increased rates of pathogen evolution ${ }^{136}$. Associated spillover followed by spillback can create scenarios that facilitate amplification and potentially selection of problematic pathogen variants ${ }^{137}$, an issue highlighted by recent documentation of human to mink to human transmission of SARS-CoV-2 (REF. $\left.{ }^{138}\right)$. Likewise, increased rates of pathogen importation provide increased opportunities for pathogen populations to evolve the ability to utilize novel vectors (as has been observed in the Americas for malaria ${ }^{129}$ ). Increased population connectivity can also enable pathogens and their vectors to shift to novel host species, from infected mosquitoes travelling on boats or in planes to agricultural pathogens being inadvertently relocated. Hosts that have not previously been exposed to such pathogens, and thus have no co-evolved defences, yet are phylogenetically and/or genetically similar to the original host are often most at risk ${ }^{139,140}$, a fact that makes homogenization of crops $^{141}$ or livestock a concern. Novel pathogen introductions can have large-scale population and ecosystem impacts, of which one famous example is the extirpation of the American chestnut tree by chestnut blight ${ }^{142}$. Changes in selection pressure resulting from changes in health-care strategies (for example, introduction of vaccination) may have the potential to select for different pathogen characteristics, and could potentially drive the evolution of virulence in pathogens ${ }^{143,144}$. connected urban areas are potential hot spots for the rapid spread of diseases such as COVID-19 and SARS, and cities can serve as a catalyst for rapid local and global transmission.

\section{Local-scale disease dynamics}

Emerging, re-emerging and endemic pathogens in human populations may exhibit distinct dynamic patterns of spread at the local scale. These patterns will be governed by demographic factors, including the effects of human behaviour on transmission (for example, school terms drive transmission of many childhood infections ${ }^{26}$ and sex-specific travel patterns may result in higher burdens of chikungunya in women in Bangladesh $^{27}$ ) and immunity (which, for immunizing infections such as measles and rotavirus infection, is, in turn, shaped by replenishment of susceptible individuals via births ${ }^{28,29}$ and depletion by vaccination where vaccines are available ${ }^{30}$ ). Transmission may also be affected by climatic variables acting spatially or over the course of the year in line with seasonal fluctuations ${ }^{31,32}$. Recent global changes have affected each of these drivers of local-scale dynamics (FIG. 3).

As school attendance not only modulates transmission of childhood infections ${ }^{26}$ but also shapes human mobility ${ }^{33}$, dramatic increases in rates of school attendance globally thus have the potential to substantially alter the dynamics of many infections. That this has yet to be documented is perhaps in part because this change has happened alongside expansion of access to vaccines that protect children against many of the relevant infections, as well as global declines in birth rates, which also facilitate control efforts by diminishing the size of the susceptible pool ${ }^{34}$. If the burden of disease is age specific, the intersection between immunity and shifting demography may be particularly marked: declining birth rates translate into a smaller pool of susceptible individuals and thus infected individuals, reducing the overall rate at which susceptible individuals become infected, and thus increasing the average age of infection or disease, as reported for dengue in Thailand ${ }^{35}$ and rubella in Costa Rica $^{36}$ as these countries went through the demographic transition. Conversely, ageing populations may increase transmission; for example, longer shedding has been suggested with increasing age for SARS-CoV-2 (REF. ${ }^{37}$ ).

Demographic changes to population size and density via urbanization may also affect dynamics. Influenza, for example, tends to exhibit more persistent outbreaks in more populous, denser urban regions ${ }^{38}$ (FIG. 2). A similar pattern was reported in the early COVID-19 pandemic ${ }^{39}$. If demographic change has importantly altered the context of infectious diseases in recent years, arguably an even larger effect is caused by changes in the occurrence of immunomodulatory infections, which, in turn, may affect other infections. For example, the emergence of HIV has amplified the burden of tuberculosis ${ }^{40}$. Mass drug administration efforts have reduced helminth prevalence, which will have knock-on effects on the burden of other infections, such as malaria, which may be increased in individuals experiencing a heavy worm burden $^{41}$; both will also intersect with the efficacy of vaccination programmes ${ }^{42}$. 


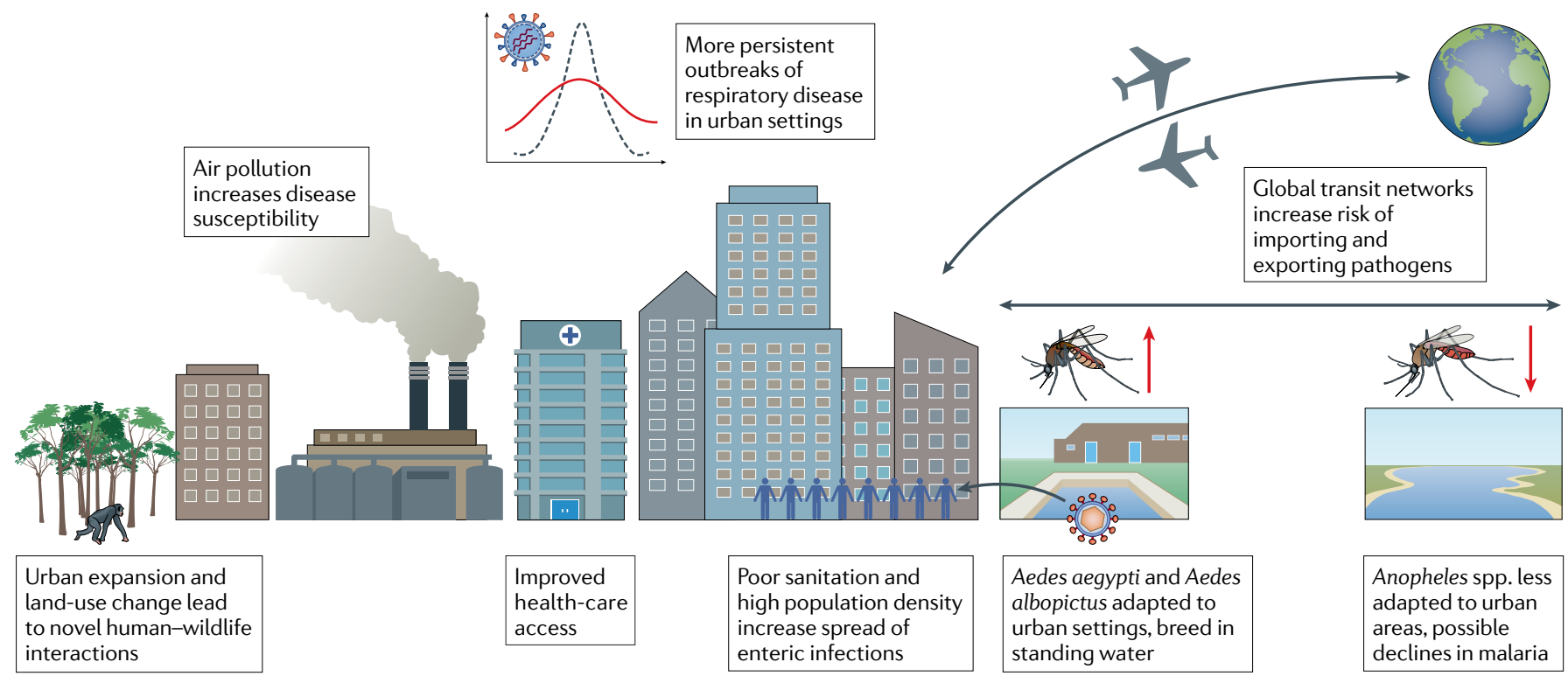

Fig. 2 | Impacts of urbanization on infectious disease. Interactions between urbanization and infectious disease are complex, with increased urbanization driving both positive and negative changes to global disease burden.

The climate plays a key role in driving the local-scale seasonal dynamics of many infectious diseases, which may thus be altered by global change in climatic conditions $s^{43,44}$. Considering these impacts requires recognizing that interactions with climate differ by pathogen type. For directly transmitted infections, the role of climate is revealed by marked latitudinal gradients in epidemic timing ${ }^{32,45}$. Several respiratory pathogens, including influenza virus, are more highly seasonal in temperate climates and exhibit greater year-round persistence in tropical locations $\mathrm{s}^{32,46}$. Climate change is expected to lead to an expansion of these tropical patterns, with possible implications for pathogen evolution ${ }^{43,47}$. At the individual level, susceptibility to respiratory viral infections may be impacted by exposure to local air pollution, which is a concern for rapidly urbanizing locations, where urban air pollution may disproportionately affect low-income communities and communities of colour ${ }^{48,49}$. For example, non-Hispanic Black and Hispanic populations in the USA were found to have higher exposure to certain $\mathrm{PM}_{2.5} \mathrm{com}$ ponents than non-Hispanic white populations ${ }^{49}$. At the same time, globally, a move to an urban location may bring benefits in terms of increased access to health care (FIG. 2).

For some bacterial and fungal diseases, climatic changes may affect the pathogen's environmental reservoir. Incidence of coccidioidomycosis (valley fever), caused by inhalation of fungal spores of Coccidioides spp., is expected to increase with climate change as the region with optimal conditions for fungal spore production expands ${ }^{50}$. Climate change may also have played a role in the emergence of the drug-resistant fungal pathogen Candida auris. C. auris emerged in several continents at the same time and has been shown to have increased thermotolerance compared with other closely related fungal species, which perhaps evolved in response to global warming ${ }^{51,52}$. This increased thermotolerance may have enabled the pathogen to jump from its environmental habitat into an intermediary avian host, given the higher body temperatures of avian fauna, before infecting humans ${ }^{52}$.

Demographic change and technological changes may alter a host's interaction with the environmental reservoir. Cholera, caused by the bacterial pathogen Vibrio cholerae, persists in the environment, particularly in aquatic settings. Changes to environmental conditions, including elevated sea temperatures, lead to increased reproduction of the pathogen and local epidemic ${ }^{53}$, with clear links to longer-term climate phenomena such as El Niñ $0^{54}$. However, improved sanitation lowers the risk of exposure to V. cholerae and has led to a decline of the disease in many locations ${ }^{53}$.

For vector-transmitted diseases, biological traits of both the vector and the pathogen may be sensitive to climate. Many transmission-related life cycle traits of the mosquito (biting rate, adult lifespan, population size and distribution) and the pathogen (extrinsic incubation rate) are temperature sensitive, and oviposition patterns depend on water availability ${ }^{55}$. Consequently, the geographical range for dengue, malaria and other vector-borne diseases ${ }^{56-58}$ is affected by the local climate, and there is substantial effort to understand how these ranges may change with climate change ${ }^{59-61}$. For certain vector-borne diseases such as Zika virus disease, climate change may lead to an expanded range ${ }^{62}$. However, for other diseases, such as malaria, climate change may shift the spatial range of the infection to higher latitudes ${ }^{63}$. As ever, the footprint of human interventions may loom larger than these changes in local conditions ${ }^{25}$.

At the local scale, one of the strongest footprints detectable on the dynamics of many endemic infections in recent years is declines in incidence associated with access to vaccinations $s^{64}$. However, the introduction of a vaccine does not imply immediate elimination. 
As vaccination coverage increases, measles outbreaks, for instance, follow a pathway towards elimination defined by declines in mean incidence but high variability in outbreak size ${ }^{34}$. Imperfect vaccine coverage may allow population susceptibility to increase such that substantial outbreaks can occur if the disease is reintroduced; for example, the 2018 measles outbreak in Madagascar, which led to more than 100,000 cases $^{65}$. Improved surveillance of the landscape of population immunity, via serological surveys, could help determine gaps in vaccination coverage ${ }^{66}$.

\section{Global spread}

As local conditions alter demographically, or as a result of climate change potentially expanding the range of locations suitable to a particular pathogen or vector, increased global connectivity will enable pathogens to reach these new environments more rapidly (FIGS 3,4). Here, we review the impact of global change on three forms of global connectivity - international travel, human migration and local-scale mobility, and the international trade of animals, animal products and plants - while considering the impact on infectious disease risk. Technological change over the past two decades has dramatically lowered the cost of international travel, while demographic change has led to heightened demand for inexpensive flights (FIG. 1 b). Demographic and climatic drivers have altered patterns of local mobility and regional migration, while rising demand and technological change have increased the trade of plants and animals. At the same time, an increasingly urban population is better connected than ever before to global travel networks (FIG. 4). These changes to global connectivity will present unique risk factors for infectious disease spread, enabling pathogens to travel further and faster than ever before.

International travel. The late twentieth century and the early twenty-first century have been marked by technological developments enabling ever swifter movement of people and pathogens over large distances - from trains to planes, and an expanding international airline network (FIG. 4). The total number of airline passengers doubled from just below two billion in 2000 to more than four billion in 2019 (FIG. 1 b). This rampant increase in global connectivity brings with it new risks from emerging pathogens (BOX 2). However, many endemic pathogens also circulate via transit routes: seasonal influenza circulation in the USA can be predicted by flight patterns ${ }^{67,68}$, with evidence that flight bans following the events of 9/11 caused a delayed outbreak, and a prolonged influenza season within the USA as measured by a $60 \%$ increase in the time to transnational spread ${ }^{68}$. Similarly, rapid global air travel is expected to have played a key role in the global spread of SARS-CoV-2. Genetic analyses demonstrate multiple introductions of SARS-CoV-2, driven by air travel, in the Middle East ${ }^{69}$, northern California ${ }^{70}$ and Brazil $^{71}$.

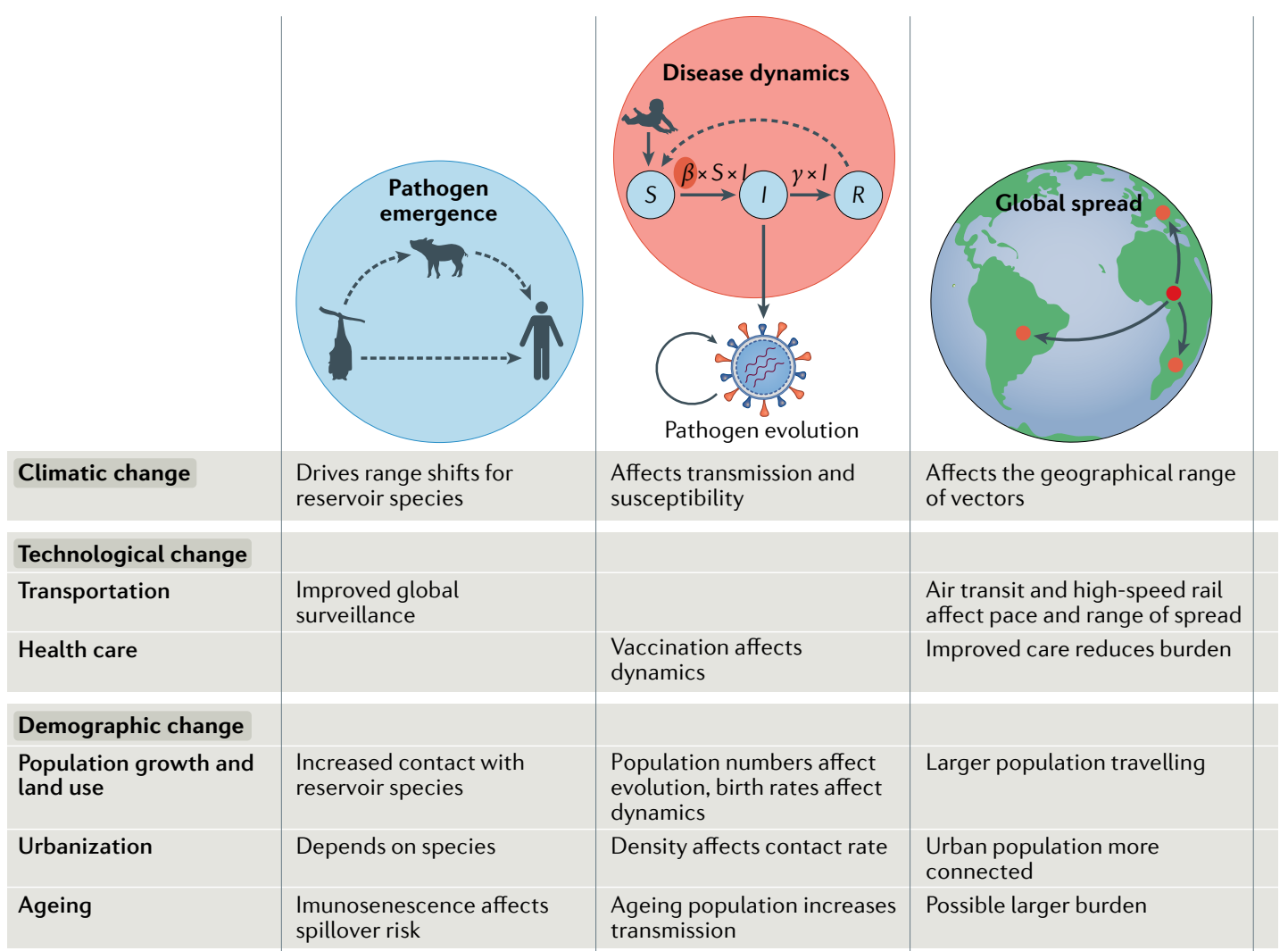

Fig. 3 | Effects of climatic, technological and demographic change on disease emergence, dynamics and spread. The table summarizes select recent global changes (rows) and their impacts on disease emergence, local-scale dynamics and global spread (columns). An example susceptible $(S)$, infected ( () , recovered $(R)$ model is shown, where $\beta$ represents the transmission rate and $\gamma$ is the recovery rate. 
a

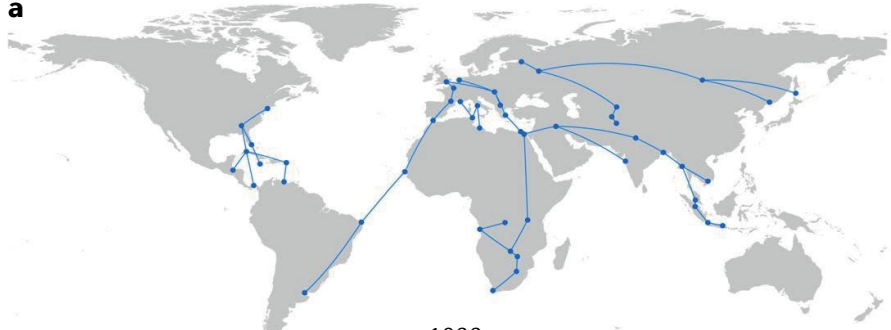

1933

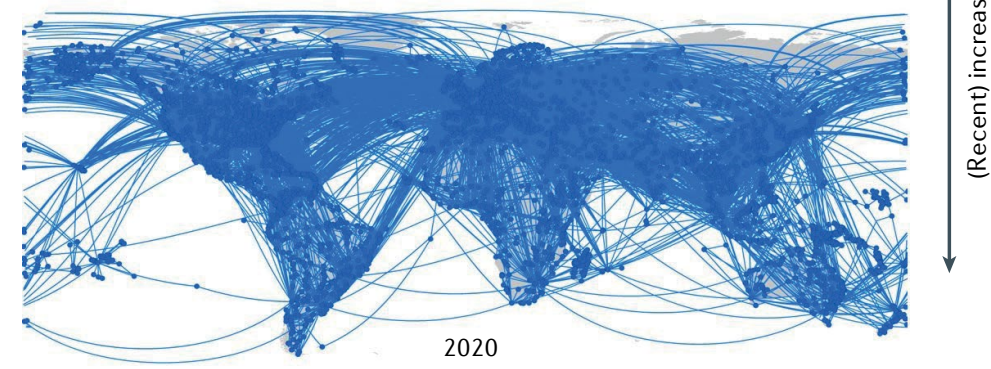

b
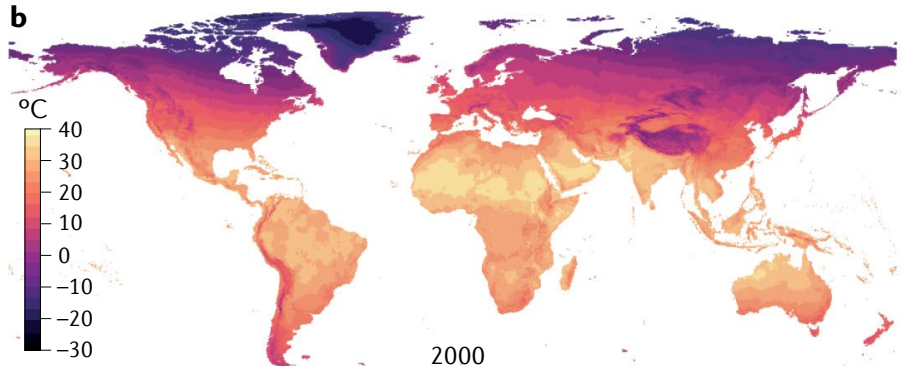

2000
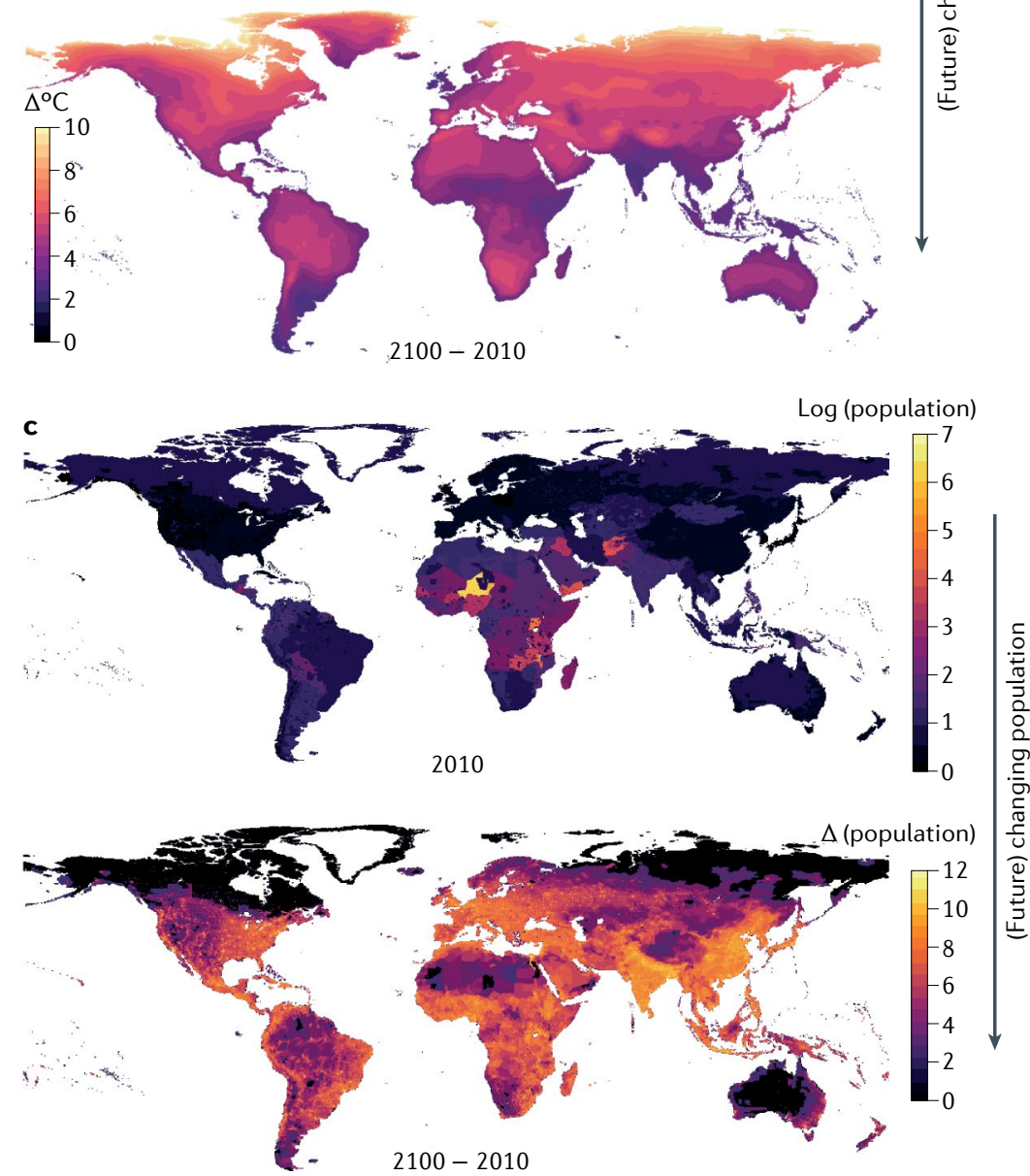

Fig. 4 | Mapping changes to travel and climate. a | The global international air travel network expanded substantially from 1933 to 2020 (data from WorldPop and $\left.\mathrm{REF}^{131}{ }^{13}\right) \cdot \mathbf{b} \mid$ Average monthly maximum temperature in 1970-2000) and difference between 2070-2100 and 1970-2000 averages (data from WorldClim, Shared Socioeconomic Pathway 3 (SSP3)). c| Population projections under SSP3 in 2010 and relative population change projected until 2100 (source NASA Socioeconomic Data and Applications Center (REF. $\left.{ }^{132}\right)$ ). Part a adapted with permission from REF. ${ }^{131}$, OUP.

International travel can lead to the global spread of vector-borne diseases via the introduction of new vectors into regions with suitable environmental conditions or the introduction of new pathogens into native and invasive vector populations. Historically, vectors have been introduced via trade routes: ships are thought to have been key to the global dispersal of Ae. aegypti and Ae. albopictus, which then became established in locations with appropriate environmental conditions ${ }^{72,73}$. Anopheles gambiae, the primary vector of malaria in Africa, was introduced into Brazil in the 1930s and became established in a region with a climate similar to that of its native Kenya ${ }^{74}$. Although malaria was already endemic in Brazil at the time, An. gambiae proved a much more effective vector, leading to a severe outbreak and a costly (but successful) eradication campaign ${ }^{73}$. There has been relatively little documented evidence of the introduction of new vectors via air travel. This is likely due to the low probability of vectors surviving the flight, and disembarking in a suitable region, in sufficient numbers to establish and drive an epidemic ${ }^{75}$. However, cases of 'airport malaria', that is, malaria transmitted within international airports, even outside endemic regions, are rare but becoming more common ${ }^{76}$.

A more feasible scenario is that air travel can bring an infected human host into contact with a native or invasive vector population that then establishes local transmission. Climate change has driven a shift in the range of several key vectors, which may make this introduction more likely. The range of the biting midge Culicoides imicola, a vector of bluetongue virus, which causes disease in ruminants, has expanded over the past few decades from sub-Saharan Africa and the Middle East into Europe, bringing a wave of bluetongue epidemics ${ }^{77}$. Following this expansion, bluetongue virus then spread outside the range of C. imicola into native populations of Culicoides spp. in more northerly regions of Europe. In terms of air travel, the 2015 Zika virus disease epidemic in the Americas may provide a recent example of a pathogen spreading into a susceptible vector population, likely facilitated by high connectivity ${ }^{78}$. Zika virus is thought to have been introduced to Brazil from French Polynesia and vectored by Aedes spp., although the volume of air travel during this period makes it almost impossible to conclusively determine the origin ${ }^{78}$. Similarly, it is hard to pinpoint the pathway via which West Nile virus was introduced into the USA in the 1990s; however, transport by either shipping (transporting vectors) or aircraft (transporting a human host) is likely ${ }^{79}$. After introduction, West Nile virus spread in the native Culex spp. mosquito population. More broadly, climate change 


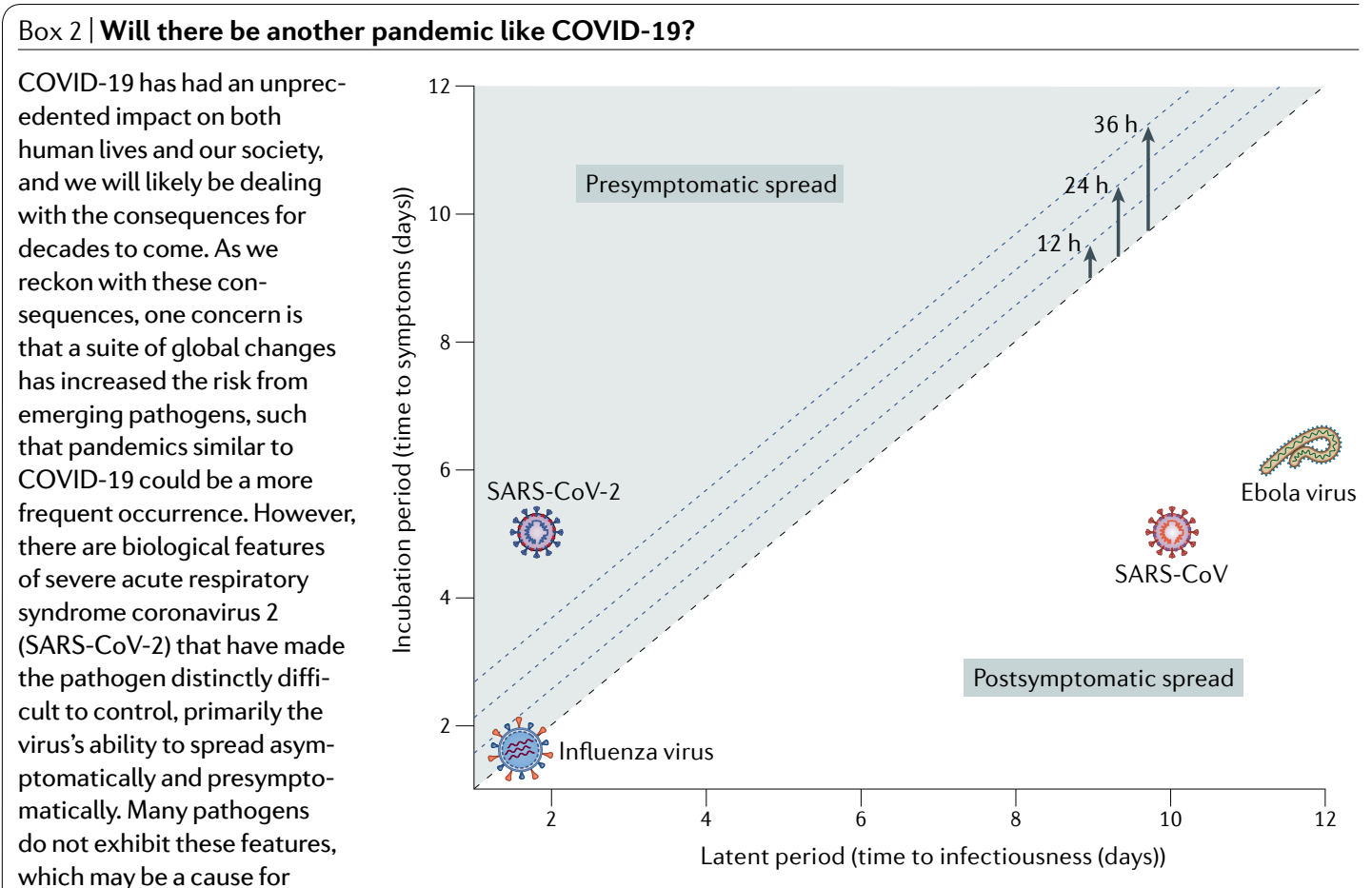

cautious optimism going forward.

The expansion of regional and global air travel, along with the increasing development of high-speed railway networks, has resulted in a substantial degree of connectivity between human populations ${ }^{73}$. At the same time, land-use change and climate change may have increased the risk of pathogen emergence. In combination, these drivers imply an era where pathogens are more likely to emerge, and more likely to spread globally on emergence. However, while the last century bore witness to several pandemics (FIG. 1), SARS-CoV-2 is unrivalled in its rapid, global reach. A key question is why SARS-CoV-2 was so successful at spreading globally and whether this was due to recent increases in global connectivity as opposed to epidemiological and biological characteristics of the virus itself $f^{145}$.

A clear distinction between SARS-CoV-2 and other recently emerged pathogens (for example, SARS-CoV and Ebola virus) is that an individual infected with SARS-CoV-2 may become infectious before developing symptoms ${ }^{146}$. This presents a unique challenge from a disease control perspective. A standard approach for limiting the onward spread of a new outbreak is to isolate infected individuals when they show symptoms. Case isolation proved successful in mitigating earlier SARS ${ }^{147}$ and Ebola virus disease ${ }^{148}$ outbreaks. However, symptoms for SARS-CoV-2 infection likely occur after an individual is already infectious ${ }^{146}$. This possible presymptomatic spread limits the efficacy of case isolation interventions as by the time the infected individual is isolated, the person may have already spread the pathogen to others $^{149}$. In the figure, we plot the time to infectiousness (latent period) against the time to symptom onset (incubation period) for four pathogens that have caused severe outbreaks in recent decades. When the latent period equals the incubation period (dashed line in the figure), symptoms occur at a similar time to infectiousness (for example, influenza). The shaded region to the right of this line in the figure indicates possible presymptomatic spread, which may be uniquely difficult to control.

The 2-3-day delay between infectiousness and symptom onset provides ample time for long-distance spread of the disease, given current transport networks (see the figure). Control policies, such as testing before travel, provide a more effective option in this context, yet developing and distributing a test takes time, during which time the disease may spread rapidly. The good news is that this presymptomatic spread appears somewhat unique to SARS-CoV-2, at least compared with other acute infections such as influenza, SARS and Ebola virus disease (FIG. 4). In comparison, asymptomatic spread explains some of the difficulty in controlling acquired immunodeficiency syndrome before antiretroviral measures were available.

complicates the picture in terms of possible future introductions. As the range of locations with environmental suitability for certain vector species changes, successful introductions of pathogens into these vector populations may become more likely ${ }^{80}$. At the same time, changes to population structure (for example, via urbanization) may alter the suitability of an environment for vector reproduction (FIG. 2).

Migration and local mobility. Human migration is an intrinsic component of population dynamics driven by socio-economic, political and environmental factors, and one that has undergone considerable upheaval in the modern era. It is estimated that globally the number of international migrants, those who intentionally relocate to a country other than their birth country, is almost 272 million, representing $3.5 \%$ of the world's population. By contrast, temporary migration, often considered 'seasonal migration', is driven largely by economic patterns, including agricultural seasons that require short periods of intense labour. The rate of migration continues to increase owing to both social, economic, political and environmental drivers in origin countries and economic opportunities, physical safety and security in destination 
countries. Projections for migration are unclear, with the UN projecting stable rates after 2050 (REF. ${ }^{81}$ ). However, climate change will likely provide an escalating push factor, with sea level rise and extreme weather events leading to forced migration from exposed regions ${ }^{82}$.

Given the movement of people between countries, there remain risks of introduction of infectious diseases, including those common and uncommon in the country of migration $^{83}$. It is possible for a infectious disease common in the source country, such as latent tuberculosis, malaria, viral hepatitis and infection with intestinal parasites, to be imported via this mechanism ${ }^{84-86}$. For example, in many destination countries, a large proportion of cases of tuberculosis are observed in the foreign-born population. However, the ultimate impact of these introduction events will depend largely on the population-level susceptibility and environmental suitability for sustained transmission in the destination country. More importantly, migrant groups often have more limited access to health care, treatment and resources, particularly those displaced, who are often provided with limited options to safely seek care and treatment ${ }^{87}$. Minimizing the impact of these possible disease threats depends on providing appropriate health care to these high-risk groups that takes into account the multifaceted social, political and economic components ${ }^{88}$.

Within-country population mobility can also play a key role in disease spread; however, it is typically difficult to track these movements. Aggregated mobile phone data are a valuable tool for tracing patterns of local mobility and predicting future outbreaks ${ }^{89}$. In recent work, mobility data have been shown to be predictive of inequities in COVID-19 burden in the USA ${ }^{90}$. Similarly, population mobility was found to predict the spread of the 2011 dengue epidemic in Pakistan ${ }^{91}$, while local travel following the Eid holidays was found to predict the spread of the chikungunya outbreak in 2017 in Bangladesh $^{92}$. As the trend of urbanization continues, mobility to and from dense urban centres (that is, megacities) will likely play a future role in local spread of infections ${ }^{92}$. Better tracking of within-country population mobility, using novel data streams, may present an opportunity for forecasting future outbreaks ${ }^{93}$.

\section{Intensification of animal and plant trade}

International trade has expanded rapidly in the modern era and has been matched by a global proliferation of infectious diseases affecting not only humans but also animals and plants ${ }^{94,95}$. Trade drives this pattern by facilitating the translocation of hosts and pathogens across the geographical and ecological boundaries that constrain their spread. The economic and environmental threats posed by trade-driven infectious diseases of plants and animals are increasingly being recognized, and calls for more stringent containment measures have intensified in recent years ${ }^{96,97}$.

Plant trade. Deliberate transport of plant products has existed since the emergence of trade. Increases in the speed of transport during modern times have allowed more live plant tissue, and as a result more viable pathogen propagules, to be transported over long distances.
Combined with the intensification of trade at the global scale, this pattern has driven a rise in long-distance transmission and disease emergence ${ }^{98,99}$. Trade drives the emergence of novel plant diseases by creating novel interactions between hosts and pathogens ${ }^{100}$. One pathway through which this can occur is the introduction of novel pathogens to native plants. For example, Xylella fastidiosa, a generalist bacterium vectored by xylemfeeding insects, was introduced into Europe in 2013 from the USA, likely as a result of trade. In Italy, X. fastidios $a$ is causing an ongoing epidemic of 'olive quick decline syndrome', resulting in severe losses of an economically and culturally important $\mathrm{crop}^{101,102}$. Trade can also drive the emergence of plant disease by introducing novel hosts to native pathogens. Eucalyptus rust, a disease caused by the fungal pathogen Austropuccinia psidii, emerged when the pathogen transferred from its native South American hosts in the myrtle family (Myrtaceae) to nonnative Eucalyptus trees (which also belong to the myrtle family) being grown on plantations ${ }^{103}$. The disease now threatens to 'spill back' into naive endemic Eucalyptus populations in Australia.

Animal and animal-product trade. Animal trade has contributed to multiple outbreaks and emergence events globally, which have had major consequences for the agricultural sector as a whole and pose substantial risk for animal and public health. Large numbers of livestock are traded annually between countries and may facilitate the spread of pathogens. Rift Valley fever, for example, is a zoonotic vector-borne viral disease causing abortion and high neonatal mortality in domestic ruminants. The disease is widespread on the African continent and has recently been detected in Saudi Arabia and Yemen. Live cattle movement between East Africa and the Arabian peninsula or from the Union of Comoros to Madagascar is thought to have contributed to the introduction of Rift Valley fever virus and caused outbreaks in these locations in 2000 (Arabian Peninsula) and 2008 (Madagascar) $^{104,105}$.

Additionally, the trade of animal-derived products such as meat may enable the movement of pathogens over large distances and between continents. For instance, African swine fever is a highly contagious viral disease affecting several members of the family Suidae, including domestic pigs and wild boars. Infection by African swine fever virus may result in up to $100 \%$ morbidity and mortality in affected pig herds and substantial economic losses for producers. In 2007, the accidental introduction of African swine fever virus to Georgia led to the first outbreak of African swine fever in Europe since the early $1990 \mathrm{~s}^{106}$. The virus, which used to occur primarily in sub-Saharan Africa, was allegedly introduced to the Caucasian peninsula through meat products contaminated with viruses closely related to the ones found in Madagascar, Mozambique or Zambia $^{107}$. Despite efforts to contain the virus, the disease has spread to more than 20 countries in Europe and Asia $^{108,109}$.

Similarly, in recent decades there has been an expansion in infections of Vibrio parahaemolyticus a bacterial pathogen found in shellfish and the leading 


\section{Box 3 | Big data for disease}

Recent technological advances in collecting, sharing and processing large datasets, from satellite images to genomes, represent a new opportunity to answer critical questions in global health. However, challenges remain, including the uneven geographical distribution of available data as well as biases in representative sampling. We highlight three areas of future growth.

\section{Serological surveys}

Serological surveys detect the presence of antibodies in blood - recent advances in testing now enable the detection of exposure to multiple pathogens with use of a small sample of blood ${ }^{150}$. Serological surveys have attracted attention during the COVID-19 pandemic as a means to track population exposure given under-reporting, although test performance characteristics differ widely between epidemiological contexts as well as the choice of assay used ${ }^{151}$. Historically, serological surveys have been financially and logistically expensive to run, but declining costs are leading to increased availability of serological data.

\section{Genomic surveillance systems}

Genomic surveillance systems are able to characterize and track the emergence of novel variants (for example, during the COVID-19 pandemic). Undoubtedly these data have enabled the rapid development of diagnostics and vaccines and, when combined with epidemiological information, are able to provide a more detailed picture of ongoing transmission dynamics. Efforts to develop national and international genomic surveillance networks are varied but with clear success stories ${ }^{152,153}$ even in low-resources settings ${ }^{154}$. However, resource limitations, including sequencing platforms, bioinformatic pipelines and the regular collection of samples for processing, continue to limit the global expansion of sequencing.

\section{Artificial intelligence and machine learning}

These techniques are frequently proposed as tools for answering key public health questions, yet specific use cases remain elusive ${ }^{155}$. Using these tools to predict viral emergence, for example, may prove difficult due to microbiological complexities and the cost of data collection ${ }^{156}$, yet could prove valuable for targeting sampling efforts ${ }^{157}$. In terms of uncovering population-level drivers of disease transmission, statistical approaches, including machine learning, can be used to leverage novel, and high-volume, data streams. However, more classical, mechanistic models may provide a more robust framework for projecting future outcomes for the disease system under demographic, technological and climatic change. Future work should aim to improve the integration of machine learning approaches within the traditional mechanistic modelling frameworks to rapidly and accurately assess prospective challenges.

Reassortment

The mixing of genetic material

of different pathogens within

an infected cell. cause of seafood-related illness globally. The pathogen is endemic to regions of the US Pacific Northwest but has recently spread to other parts of the USA, Europe and South America ${ }^{110,111}$. The concerning increase in $V$. parahaemolyticus infection is expected to have several drivers connected to global change. Declines in sea ice have increased ship traffic through the Bering Strait, with cargo ships possibly transporting $V$. parahaemolyticus in ballast water. At the same time, increasing sea temperatures may have increased the global environmental suitability for $V$. parahaemolyticus in the marine environment ${ }^{110}$. Finally, dispersal of the pathogen may have occurred via increasing global trade in shellfish, with evidence suggesting possible dispersal via Manila clams introduced into Spain from Canada ${ }^{111}$. This combination of possible drivers speaks to the complexity of understanding infectious disease risk in an era of global change, and the necessity of exploring concurrent changes.

Transboundary spread of diseases through legal and illegal trade of live animals may also have important consequences for biodiversity on a global scale. For example, the amphibian trade contributed to the expansion of novel strains of the fungal pathogen genus Batrachochytrium into naive hosts, devastating wild amphibian populations globally ${ }^{112}$. Conversely, infectious diseases also hamper trade, resulting in indirect economic losses in affected populations. Foot and mouth disease virus is a major reason for trade restrictions on livestock. While endemic in certain countries in Asia and Africa, foot and mouth disease virus causes outbreaks in naive populations, resulting in large economic losses ${ }^{13}$. While trade is a major driver of pathogen spread, food animal production has transformed in recent history into large-scale intensified systems with high-density, genetically homogenous populations, ideal for pathogen emergence and maintenance ${ }^{114}$. Critically, animal production systems often serve as the interface between wild and human populations, and multiple viral spillover events have occurred at this nexus. Nipah virus spilled over from fruit bats to the domestic pig population multiple times before subsequently infecting humans ${ }^{115}$. Pandemic variants of human influenza A virus are often the result of reassortment between human and avian viruses, with both domestic poultry and wild birds posited to play a role ${ }^{116-118}$. A non-viral example is the spillover of antimicrobial-resistant pathogens from livestock into humans: intensive antibiotic use in industrialized and smallholder livestock production systems to promote growth and prevent infections has been linked to the emergence of antibiotic resistance in humans ${ }^{119}$. Tackling emergence and disease spread in animal systems will require rethinking both food animal production and global trade of animals.

\section{A new era of infectious disease}

In recent decades, declines in mortality and morbidity, particularly childhood mortality, have been one of the great triumphs of public health. Greater access to care, such as therapeutics (including antibiotics), improved sanitation and the development of vaccines ${ }^{120}$ have been core drivers of this progress. Even as medical advances in the twenty-first century have spurred advances in population health, inequalities in access to these advances remain widespread between and within countries ${ }^{121}$. Reducing inequities in access to health care and improving surveillance and monitoring for infectious diseases in low-income and middle-income countries, and in underserved populations within countries, should be a priority in tackling pathogen emergence and spread.

While life expectancy continues to increase, and life years lost to infectious diseases decline, the new threat of infectious disease will likely come from emerging and re-emerging infections. Climate change, rapid urbanization and changing land-use patterns will increase the risk of disease emergence in the coming decades. Climate change, in particular, may alter the range of global pathogens, allowing infections, particularly vector-borne infections, to expand into new locations. A continued uptick in global travel, trade and mobility will transport pathogens rapidly, following emergence. However, there are counterpoints to this trend: the rapid growth of connectivity observed in the early twenty-first century may stabilize, and structural changes wrought during the COVID-19 pandemic may persist ${ }^{122}$. Increased investment in outbreak response, such as the recent formation of the WHO Hub for Pandemic and Epidemic 
Multiplex serology

The measurement of antibody responses to multiple pathogens simultaneously.
Intelligence, could help mitigate the threat from future emerging infections. In addition, efforts to develop universal vaccines (that is, vaccines that engender immunity against all strains of influenza viruses or coronaviruses, for example) could provide a monumental leap forward in tackling present and future infections ${ }^{123}$.

A changing world requires changing science to evaluate future risks from infectious disease. Future work needs to explicitly address concurrent changes: how shifting patterns of demographic, climatic and technological factors may collectively affect the risk of pathogen emergence, alterations to dynamics and global spread. More forward-looking research, to contend with possible future outcomes, is required in addition to the retroactive analyses that typically dominate the literature. Increasing attention needs to be paid to pathogens currently circulating in both wild and domestic animal populations, especially in cases where agriculture is expanding into native species' habitats and, conversely, invasive species are moving into populous regions due to climate change. As the battle against certain long-term endemic infections is won, institutional structures built to address these old enemies can be co-opted and adapted for emerging threats. At the same time, new technologies, including advances in data collection and surveillance, need to be harnessed (BOX 3). There is much recent innovation around surveillance, from reinterpreting information available from classic tools such as $\mathrm{PCR}^{124}$ to leveraging multiplex serology approaches to identify anomalies that might suggest pathogen emergence, and there is increasing interest in integrating multiple surveillance platforms (from genomic to case data) to better understand pathogen spread. Finally, future research needs to align with a global view of disease risk. In an increasingly connected world, the risk from infectious disease is globally shared. The COVID-19 pandemic, including the rapid global circulation of evolved strains, highlights the need for a collaborative, worldwide framework for infectious disease research and control.

\section{Published online 13 October 2021}

1. Roeder, P., Mariner, J. \& Kock, R. Rinderpest: the veterinary perspective on eradication. Philos. Trans. R. Soc. Lond. B Biol. Sci. 368, 20120139 (2013).

2. Karesh, W. B. et al. Ecology of zoonoses: natural and unnatural histories. Lancet 380, 1936-1945 (2012)

3. Plowright, R. K. et al. Pathways to zoonotic spillover. Nat. Rev. Microbiol. 15, 502-510 (2017).

4. Zhou, P. \& Shi, Z.-L. SARS-CoV-2 spillover events. Science 371, 120-122 (2021).

5. Lloyd-Smith, J. O. et al. Epidemic dynamics at the human-animal interface. Science 326, 1362-1367 (2009).

6. Brashares, J. S. et al. Bushmeat hunting, wildlife declines, and fish supply in West Africa. Science 306. 1180-1183 (2004).

7. Parashar, U. D. et al. Case-control study of risk factors for human infection with a new zoonotic paramyxovirus, Nipah Virus, during a 1998-1999 outbreak of severe encephalitis in Malaysia. J. Infect. Dis. 181 1755-1759 (2000).

8. Field, H. et al. The natural history of Hendra and Nipah viruses. Microbes Infect. 3, 307-314 (2001).

9. Pitzer, V. E. et al. High turnover drives prolonged persistence of influenza in managed pig herds. J. R. Soc. Interface 13, 20160138 (2016)

10. Jones, B. A. et al. Zoonosis emergence linked to agricultural intensification and environmental change. Proc. Natl Acad. Sci. USA 110, 8399-8404 (2013).

11. van Boeckel, T. et al. Global trends in antimicrobial resistance in animals in low-and middle-income countries. Int. J. Infect. Dis. 101, 19 (2020).

12. Rimoin, A. W. et al. Major increase in human monkeypox incidence 30 years after smallpox vaccination campaigns cease in the Democratic Republic of Congo. Proc. Natl Acad. Sci. USA 107 16262-16267 (2010).

13. Aw, D., Silva, A. B. \& Palmer, D. B. Immunosenescence: emerging challenges for an ageing population. Immunology 120, 435-446 (2007).

14. Nikolich-Žugich, J. The twilight of immunity: emerging concepts in aging of the immune system. Nat. Immunol. 19, 10-19 (2018).

15. Laxminarayan, R. et al. Antibiotic resistance-the need for global solutions. Lancet Infect. Dis. 13, 1057-1098 (2013).

16. Talisuna, A. O., Bloland, P. \& D’Alessandro, U. History, dynamics, and public health importance of malaria parasite resistance. Clin. Microbiol. Rev. 17, 235-254 (2004).

17. Carlson, C. J. et al. Climate change will drive novel cross-species viral transmission. Preprint at bioRxiv https://doi.org/10.1101/2020.01.24.918755 (2020)

18. Patz, J. A., Epstein, P. R., Burke, T. A. \& Balbus, J. M. Global climate change and emerging infectious diseases. JAMA 275, 217-223 (1996).

19. Martin, G. et al. Climate change could increase the geographic extent of Hendra virus spillover risk. Ecohealth 15, 509-525 (2018).
20. Yuen, K. Y. et al. Hendra virus: epidemiology dynamics in relation to climate change, diagnostic tests and control measures. One Health 12, 100207 (2021). Martin et al. (2018) and Yuen et al. (2021) detail the link between climate change and recent Hendra virus spillover.

21. Brook, C. E. et al. Accelerated viral dynamics in bat cell lines, with implications for zoonotic emergence. eLife 9, e48401 (2020).

22. Gubler, D. J. Dengue, urbanization and globalization: the unholy trinity of the 21 st century. Trop. Med. Health 39, S3-S11 (2011)

23. Li, Y. et al. Urbanization increases Aedes albopictus larval habitats and accelerates mosquito development and survivorship. PLoS Negl. Trop. Dis. 8, e3301 (2014).

24. Rose, N. H. et al. Climate and Urbanization drive mosquito preference for humans. Curr. Biol. 30 3570-3579.e6 (2020).

25. Tatem, A. J., Gething, P. W., Smith, D. L. \& Hay, S. I. Urbanization and the global malaria recession. Malar. J. 12, 133 (2013).

26. Mahmud, A. S., Metcalf, C. J. E. \& Grenfell, B. T. Comparative dynamics, seasonality in transmission, and predictability of childhood infections in Mexico. Epidemiol. Infect. 145, 607-625 (2017).

27. Salje, H. et al. How social structures, space, and behaviors shape the spread of infectious diseases using chikungunya as a case study. Proc. Natl Acad. Sci. USA 113, 13420-13425 (2016)

This article shows how interactions between the characteristics of an individual and that individual's environment contribute to disease dynamics.

28. Pitzer, V. E. et al. Demographic variability, vaccination, and the spatiotemporal dynamics of rotavirus epidemics. Science 325, 290-294 (2009).

29. Earn, D. J., Rohani, P., Bolker, B. M. \& Grenfell, B. T. A simple model for complex dynamical transitions in epidemics. Science 287, 667-670 (2000).

30. Ferrari, M. J., Grenfell, B. T. \& Strebel, P. M. Think globally, act locally: the role of local demographics and vaccination coverage in the dynamic response of measles infection to control. Philos. Trans. R. Soc Lond. B Biol. Sci. 368, 20120141 (2013).

31. Thompson, C. N et al. The impact of environmental and climatic variation on the spatiotemporal trends of hospitalized pediatric diarrhea in Ho Chi Minh City, Vietnam. Health Place. 35, 147-154 (2015).

32. Baker, R. E. et al. Epidemic dynamics of respiratory syncytial virus in current and future climates. Nat. Commun. 10, 5512 (2019).

33. Wesolowski, A. et al. Multinational patterns of seasonal asymmetry in human movement influence infectious disease dynamics. Nat. Commun. 8, 2069 (2017).

34. Graham, M. et al. Measles and the canonical path to elimination. Science 364, 584-587 (2019).

35. Cummings, D. A. T. et al. The impact of the demographic transition on dengue in Thailand: insights from a statistical analysis and mathematical modeling. PLoS Med. 6, e1000139 (2009).

36. Metcalf, C. J. E. et al. Structured models of infectious disease: inference with discrete data. Theor. Popul. Biol. 82, 275-282 (2012).

37. Cevik, M. et al. SARS-CoV-2, SARS-CoV, and MERS $\mathrm{CoV}$ viral load dynamics, duration of viral shedding, and infectiousness: a systematic review and meta-analysis. Lancet Microbe 2, e13-e22 (2021).

38. Dalziel, B. D. et al. Urbanization and humidity shape the intensity of influenza epidemics in U.S. cities. Science 362, 75-79 (2018).

This study describes distinct patterns of influenza outbreaks in urban locations.

39. Rader, B. et al. Crowding and the shape of COVID-19 epidemics. Nat. Med. 26, 1829-1834 (2020).

40. Kwan, C. K. \& Ernst, J. D. HIV and tuberculosis a deadly human syndemic. Clin. Microbiol. Rev. 24 351-376 (2011)

41. Nkuo-Akenji, T. K., Chi, P. C., Cho, J. F. Ndamukong, K. K. J. \& Sumbele, I. Malaria and helminth co-infection in children living in a malaria endemic setting of mount Cameroon and predictors of anemia. J. Parasitol. 92, 1191-1195 (2006).

42. Hartmann, W. et al. Helminth infections suppress the efficacy of vaccination against seasonal influenza. Cell Rep. 29, 2243-2256.e4 (2019).

43. Mahmud, A. S., Martinez, P. P., He, J. \& Baker, R. E. The impact of climate change on vaccine-preventable diseases: insights from current research and new directions. Curr. Env. Health Rep. 7, 384-391 (2020)

44. Baker, R. E., Yang, W., Vecchi, G. A., Metcalf, C. J. E. $\&$ Grenfell, B. T. Assessing the influence of climate on wintertime SARS-CoV-2 outbreaks. Nat. Commun. 12 846 (2021).

45. Tamerius, J. D. et al. Environmental predictors of seasonal influenza epidemics across temperate and tropical climates. PLoS Pathog. 9, e1003194 (2013).

46. Viboud, C., Alonso, W. J. \& Simonsen, L. Influenza in tropical regions. PLoS Med. 3, e89 (2006).

47. Baker, R. E. et al. Implications of climatic and demographic change for seasonal influenza dynamics and evolution. Preprint at medRxiv https://doi.org/ 10.1101/2021.02.11.21251601 (2021).

48. Ciencewicki, J. \& Jaspers, I. Air pollution and respiratory viral infection. Inhal. Toxicol. 19, 1135-1146 (2007).

49. Bell, M. L. \& Ebisu, K. Environmental inequality in exposures to airborne particulate matter components in the United States. Environ. Health Perspect. 120, 1699-1704 (2012).

50. Gorris, M. E., Treseder, K. K., Zender, C. S. \& Randerson, J. T. Expansion of coccidioidomycosis endemic regions in the United States in response to climate change. Geohealth 3, 308-327 (2019). This study is one of the first to describe the link between climate change and valley fever

51. Du, H. et al. Candida auris: epidemiology, biology, antifungal resistance, and virulence. PLoS Pathog. 16 e1008921 (2020). 
52. Casadevall, A., Kontoyiannis, D. P. \& Robert, V. On the emergence of Candida auris: climate change, azoles, swamps, and birds. mBio 10, e01397 (2019).

53. Colwell, R. R. Global climate and infectious disease: the cholera paradigm. Science 274, 2025-2031 (1996).

54. Koelle, K., Rodó, X., Pascual, M., Yunus, M. \& Mostafa, G. Refractory periods and climate forcing in cholera dynamics. Nature 436, 696-700 (2005). This study highlights the importance of the interplay between intrinsic (temporary immunity) and extrinsic (climatic variability) factors in determining disease dynamics.

55. Mordecai, E. A. et al. Detecting the impact of temperature on transmission of Zika, dengue, and chikungunya using mechanistic models. PLoS Negl. Trop. Dis. 11, e0005568 (2017).

56. Rocklöv, J. \& Dubrow, R. Author correction: climate change: an enduring challenge for vector-borne disease prevention and control. Nat. Immunol. 21, 695 (2020).

57. Brady, O. J. et al. Global temperature constraints on Aedes aegypti and Ae. albopictus persistence and competence for dengue virus transmission. Parasit. Vectors 7, 338 (2014).

58. Kraemer, M. U. G. et al. The global distribution of the arbovirus vectors Aedes aegypti and Ae. albopictus. elife 4, e08347 (2015).

59. Hales, S., de Wet, N., Maindonald, J. \& Woodward, A. Potential effect of population and climate changes on global distribution of dengue fever: an empirical model. Lancet 360, 830-834 (2002).

60. Wagner, C. E. et al. Climatological, virological and sociological drivers of current and projected dengue fever outbreak dynamics in Sri Lanka. J. R. Soc. Interface 17, 20200075 (2020).

61. Couper, L. I., MacDonald, A. J. \& Mordecai, E. A. Impact of prior and projected climate change on US Lyme disease incidence. Glob. Chang. Biol. 27 738-754 (2021).

62. Ryan, S. J. et al. Warming temperatures could expose more than 1.3 billion new people to Zika virus risk by 2050. Glob. Chang. Biol. 27, 84-93 (2021).

63. Ryan, S. J., Lippi, C. A. \& Zermoglio, F. Shifting transmission risk for malaria in Africa with climate change: a framework for planning and intervention. Malar. J. 19, 170 (2020).

64. Li, X. et al. Estimating the health impact of vaccination against ten pathogens in 98 low-income and middleincome countries from 2000 to 2030: a modelling study. Lancet 397, 398-408 (2021).

65. Mensah, K. et al. Seasonal gaps in measles vaccination coverage in Madagascar. Vaccine 37, 2511-2519 (2019)

66. Metcalf, C. J. E. et al. Use of serological surveys to generate key insights into the changing global landscape of infectious disease. Lancet 388, 728-730 (2016)

67. Crêpey, P. \& Barthélemy, M. Detecting robust patterns in the spread of epidemics: a case study of influenza in the United States and France. Am. J. Epidemiol. 166, 1244-1251 (2007)

68. Brownstein, J. S., Wolfe, C. J. \& Mandl, K. D. Empirical evidence for the effect of airline travel on inter-regiona influenza spread in the United States. PLoS Med. 3. e401 (2006)

69. Tayoun, A. A. et al. Multiple early introductions of SARS-CoV-2 into a global travel hub in the Middle East. Sci. Rep. 10, 17720 (2020).

70. Deng, X. et al. Genomic surveillance reveals multiple introductions of SARS-CoV-2 into northern California. Science 369, 582-587 (2020).

71. Candido, D. S. et al. Evolution and epidemic spread of SARS-CoV-2 in Brazil. Science 369, 1255-1260 (2020).

72. Lounibos, L. P. Invasions by insect vectors of human disease. Annu. Rev. Entomol. 47, 233-266 (2002).

73. Tatem, A. J., Hay, S. I. \& Rogers, D. J. Global traffic and disease vector dispersal. Proc. Natl Acad. Sci. USA $103,6242-6247$ (2006).

74. Killeen, G. F., Fillinger, U., Kiche, I., Gouagna, L. C. \& Knols, B. G. J. Eradication of Anopheles gambiae from Brazil: lessons for malaria control in Africa? Lancet Infect. Dis. 2, 618-627 (2002).

75. Tatem, A. J. et al. Air travel and vector-borne disease movement. Parasitology 139, 1816-1830 (2012).

76. Huang, Z. \& Tatem, A. J. Global malaria connectivity through air travel. Malar. J. 12, 269 (2013).

77. Purse, B. V., Rogers, D. J., Mellor, P. S., Baylis, M. \& Mertens, P. P. C. Bluetongue virus and climate change. in Bluetongue (eds Mellor, P. S., Baylis, M. \& Mertens, P. P. C.) 343-364 (Elsevier, 2009). This study describes the role of climate change in the geographical expansion of bluetongue epidemics.
78. Massad, E. et al. On the origin and timing of Zika virus introduction in Brazil. Epidemiol. Infect. 145 , 2303-2312 (2017).

79. Kilpatrick, A. M. Globalization, land use, and the invasion of West Nile virus. Science 334, 323-327 (2011).

80. Mordecai, E. A., Caldwell, J. M. ¿ Grossman, M. K. Thermal biology of mosquito-borne disease. Ecol. Lett. 22, 1690-1708 (2019)

81. United Nations. World Population Prospects 2019 (2019).

82. Wrathall, D. J. et al. Meeting the looming policy challenge of sea-level change and human migration. Nat. Clim. Chang. 9, 898-901 (2019)

83. Gushulak, B. D. \& MacPherson, D. W. Globalization of infectious diseases: the impact of migration. Clin. Infect. Dis. 38, 1742-1748 (2004).

84. Soto, S. M. Human migration and infectious diseases. Clin. Microbiol. Infect. 15 (Suppl. 1), 26-28 (2009).

85. Monge-Maillo, B. et al. Imported infectious diseases in mobile populations, Spain. Emerg. Infect. Dis. 15 1745-1752 (2009).

86. Castelli, F. $\&$ Sulis, G. Migration and infectious diseases. Clin. Microbiol. Infect. 23, 283-289 (2017)

87. Bhatia, A. et al. The Rohingya in Cox's Bazar: when the stateless seek refuge. Health Hum. Rights 20 105-122 (2018)

88. Chin, T., Buckee, C. O. \& Mahmud, A. S. Quantifying the success of measles vaccination campaigns in the Rohingya refugee camps. Epidemics 30, 100385 (2020).

89. Wesolowski, A., Buckee, C. O., Engø-Monsen, K. \& Metcalf, C. J. E. Connecting mobility to infectious diseases: the promise and limits of mobile phone data. J. Infect. Dis. 214, S414-S420 (2016).

90. Chang, S. et al. Mobility network models of COVID-19 explain inequities and inform reopening. Nature 589 82-87 (2021) This study uses high-resolution mobility data to explain inequities in COVID-19 burden.

91. Wesolowski, A. et al. Impact of human mobility on the emergence of dengue epidemics in Pakistan. Proc. Nat Acad. Sci. USA 112, 11887-11892 (2015).

92. Mahmud, A. S. et al. Megacities as drivers of national outbreaks: The 2017 chikungunya outbreak in Dhaka Bangladesh. PLoS Negl. Trop. Dis. 15, e0009106 (2021).

93. Buckee, C. O. et al. Aggregated mobility data could help fight COVID-19. Science 368, 145-146 (2020).

94. Perrings, C. Options for managing the infectious animal and plant disease risks of international trade. Food Security 8, 27-35 (2016).

95. Smith, K. F. et al. Ecology. Reducing the risks of the wildlife trade. Science 324, 594-595 (2009).

96. Perrings, C., Levin, S. \& Daszak, P. The economics of infectious disease, trade and pandemic risk. Ecohealth 15, 241-243 (2018)

97. Pavlin, B. I., Schloegel, L. M. \& Daszak, P. Risk of importing zoonotic diseases through wildlife trade, United States. Emerg. Infect. Dis. J. 15, 1721 (2009).

98. Santini, A., Liebhold, A., Migliorini, D. \& Woodward, S. Tracing the role of human civilization in the globalization of plant pathogens. ISME J. 12, 647-652 (2018).

99. Levine, J. M. \& D’Antonio, C. M. Forecasting biological invasions with increasing international trade. Conserv. Biol. 17, 322-326 (2003).

This article gives a quantitative forecast of the impact of international trade on the introduction of plant pathogens.

100. Parker, I. M. \& Gilbert, G. S. The evolutionary ecology of novel plant-pathogen interactions. Annu. Rev. Ecol. Evol. Syst. 35, 675-700 (2004).

101. Landa, B. B. et al. Emergence of a plant pathogen in Europe associated with multiple intercontinental introductions. Appl. Environ. Microbiol. https:// doi.org/10.1128/AEM.01521-19 (2020).

102. Frisullo, S., Camele, I., Agosteo, G. E., Boscia, D. \& Martelli, G. P. Brief historical account of olive leaf scorch ('brusca') in the Salento Peninsula of Italy and state-of-the-art of the olive quick decline syndrome. J. Plant. Pathol. 96, 441-449 (2014).

103. Coutinho, T. A., Wingfield, M. J., Alfenas, A. C. $\&$ Crous, P. W. Eucalyptus rust: a disease with the potential for serious international implications. Plant. Dis. 82, 819-825 (1998).

104. Shoemaker, T. et al. Genetic analysis of viruses associated with emergence of Rift Valley fever in Saudi Arabia and Yemen, 2000-01. Emerg. Infect. Dis. 8 1415-1420 (2002).

105. Lancelot, R. et al. Drivers of Rift Valley fever epidemics in Madagascar. Proc. Natl Acad. Sci. USA 114 938-943 (2017)
106. Costard, S., Mur, L., Lubroth, J., Sanchez-Vizcaino, J. M. \& Pfeiffer, D. U. Epidemiology of African swine fever virus. Virus Res. 173, 191-197 (2013).

107. Rowlands, R. J. et al. African swine fever virus isolate Georgia, 2007. Emerg. Infect. Dis. 14, 1870-1874 (2008).

108. Mighell, E. \& Ward, M. P. African swine fever spread across Asia, 2018-2019. Transbound. Emerg. Dis. https://doi.org/10.1111/tbed.14039 (2021).

109. European Food Safety Authority (EFSA). et al. Epidemiological analysis of African swine fever in the European Union (September 2019 to August 2020). EFSA J. 19, e06572 (2021).

110. Abanto, M., Gavilan, R. G., Baker-Austin, C. Gonzalez-Escalona, N. \& Martinez-Urtaza, J. Global expansion of Pacific Northwest Vibrio parahaemolyticus sequence type 36. Emerg. Infect. Dis. 26, 323-326 (2020).

111. Martinez-Urtaza, J. et al. Genomic variation and evolution of -Vibrio parahaemolyticus ST36 over the course of a transcontinental epidemic expansion. mBio https://doi.org/10.1128/mBio.01425-17 (2017). Abanto et al. (2020) and Martinez-Urtaza et al. (2017) discuss how global trade and climate change have led to the expansion of $V$. parahaemolyticus.

112. Fisher, M. C. \& Garner, T. W. J. Chytrid fungi and global amphibian declines. Nat. Rev. Microbiol. 18 332-343 (2020)

113. Knight-Jones, T. J. D. \& Rushton, J. The economic impacts of foot and mouth disease - what are they, how big are they and where do they occur? Prev. Vet. Med. 112, 161-173 (2013)

114. Robinson, T. P. et al. Antibiotic resistance: mitigation opportunities in livestock sector development. Animal 11, 1-3 (2017).

115. Pulliam, J. R. C. et al. Agricultural intensification, priming for persistence and the emergence of Nipah virus: a lethal bat-borne zoonosis. J. R. Soc. Interface 9, 89-101 (2012)

116. Rambaut, A. et al. The genomic and epidemiological dynamics of human influenza A virus. Nature $\mathbf{4 5 3}$ 615-619 (2008)

117. Olsen, B. et al. Global patterns of influenza a virus in wild birds. Science 312, 384-388 (2006).

118. Li, Y. et al. Continued evolution of H5N1 influenza viruses in wild birds, domestic poultry, and humans in China from 2004 to 2009. J. Virol. 84, 8389-8397 (2010).

119. Food and Agriculture Organization of the United Nations. Drivers, Dynamics and Epidemiology of Antimicrobial Resistance in Animal Production. (Food and Agriculture Organization, 2018).

120. Metcalf, C. J. E. et al. Transport networks and inequities in vaccination: remoteness shapes measles vaccine coverage and prospects for elimination across Africa. Epidemiol. Infect. 143, 1457-1466 (2015).

121. Hotez, P. J. Globalists versus nationalists: bridging the divide through blue marble health. PLoS Negl. Trop. Dis. 13, e0007156 (2019).

122. Antràs, P. De-globalisation? Global value chains in the post-COVID-19 age. National Bureau of Economic Research https://www.nber.org/papers/w28115 (2020).

123. Burton, D. R. \& Topol, E. J. Variant-proof vaccines invest now for the next pandemic. Nature https:// doi.org/10.1038/d41586-021-00340-4 (2021).

124. Hay, J. A. et al. Estimating epidemiologic dynamics from cross-sectional viral load distributions. Science https://doi.org/10.1126/science.abh0635 (2021).

125. Wagner, D. M. et al. Yersinia pestis and the Plague of Justinian 541-543 AD: a genomic analysis. Lancet Infect. Dis. 14, 319-326 (2014).

126. Alfani, G. \& Murphy, T. E. Plague and lethal epidemics in the pre-industrial world. J. Econ. Hist. 77, 314-343 (2017).

127. Harper, K. Pandemics and passages to late antiquity: rethinking the plague of c. 249-270 described by Cyprian. J. Rom. Archaeol. 28, 223-260 (2015).

128. Duncan-Jones, R. P. The impact of the Antonine plague. J. Rom. Archaeol. 9, 108-136 (1996).

129. Molina-Cruz, A., Zilversmit, M. M., Neafsey, D. E. Hartl, D. L. \& Barillas-Mury, C. Mosquito vectors and the globalization of Plasmodium falciparum malaria. Annu. Rev. Genet. 50, 447-465 (2016).

130. Guan, Y. et al. Molecular epidemiology of the novel coronavirus that causes severe acute respiratory syndrome. Lancet 363, 99-104 (2004).

131. Tatem, A. J. Mapping population and pathogen movements. Int. Health 6, 5-11 (2014).

132. Gao, J. Global 1-km downscaled population base year and projection grids based on the shared socioeconomic pathways, revision 01. NASA Socioeconomic Data and 
Applications Center (SEDAC) https://doi.org/10.7927/ q7z9-9r69 (2020).

133. Miller, I. F. \& Metcalf, C. J. E. Evolving resistance to pathogens. Science 363, 1277-1278 (2019).

134. Park, M., Loverdo, C., Schreiber, S. J. \&

Lloyd-Smith, J. O. Multiple scales of selection influence the evolutionary emergence of novel pathogens. Philos. Trans. R. Soc. Lond. B Biol. Sci. 368 , 20120333 (2013).

135. Kemp, S. A. et al. SARS-CoV-2 evolution during treatment of chronic infection. Nature 592, 277-282 (2021).

136. Zhan, J., Thrall, P. H., Papaïx, J., Xie, L. \& Burdon, J. J. Playing on a pathogen's weakness: using evolution to guide sustainable plant disease control strategies. Annu. Rev. Phytopathol. 53, 19-43 (2015).

137. Olival, K. J. et al. Possibility for reverse zoonotic transmission of SARS-CoV-2 to free-ranging wildlife: a case study of bats. PLoS Pathog. 16, e1008758 (2020).

138. Oude Munnink, B. B. et al. Transmission of SARS CoV-2 on mink farms between humans and mink and back to humans. Science 371, 172-177 (2021).

139. Shaw, L. P. et al. The phylogenetic range of bacterial and viral pathogens of vertebrates. Mol. ECol. 29 3361-3379 (2020)

140. Gilbert, G. S. $\&$ Webb, C. O. Phylogenetic signal in plant pathogen-host range. Proc. Natl Acad. Sci. USA 104, 4979-4983 (2007).

141. Gibson, A. K. \& Nguyen, A. E. Does genetic diversity protect host populations from parasites? A metaanalysis across natural and agricultural systems. Evol. Lett. 5, 16-32 (2021).

142. Rigling, D. \& Prospero, S. Cryphonectria parasitica, the causal agent of chestnut blight: invasion history, population biology and disease control. Mol. Plant. Pathol. 19, 7-20 (2018).

143. Gandon, S., Mackinnon, M. J., Nee, S. \& Read, A. F. Imperfect vaccines and the evolution of pathogen virulence. Nature 414, 751-756 (2001).

144. Miller, I. F. \& Metcalf, C. J. Vaccine-driven virulence evolution: consequences of unbalanced reductions in mortality and transmission and implications for pertussis vaccines. J. R. Soc. Interface 16, 20190642 (2019).

145. Fraser, C., Riley, S., Anderson, R. M. \& Ferguson, N. M. Factors that make an infectious disease outbreak controllable. Proc. Natl Acad. Sci. USA 101, 6146-6151 (2004)

146. Bar-On, Y. M., Flamholz, A., Phillips, R. \& Milo, R. Science forum: SARS-CoV-2 (COVID-19) by the numbers. eLife 9, e57309 (2020).

147. Hollingsworth, T. D., Ferguson, N. M. \& Anderson, R. M. Will travel restrictions control the international spread of pandemic influenza? Nat. Med. 12, 497-499 (2006).

148. Dhillon, R. S., Srikrishna, D. \& Sachs, J. Controlling Ebola: next steps. Lancet 384, 1409-1411 (2014).

149. Hellewell, J. et al. Feasibility of controlling COVID-19 outbreaks by isolation of cases and contacts. Lancet Glob. Health 8, e488-e496 (2020).

150. Xu, G. J. et al. Viral immunology. Comprehensive serological profiling of human populations using a synthetic human virome. Science 348 , aaa0698 (2015).

This study presents a highly multiplexed, peptidelevel serological assay to characterize prior exposure to all known viruses.

151. Takahashi, S., Greenhouse, B. \& Rodríguez-Barraquer, I. Are SARS-CoV-2 seroprevalence estimates biased? J. Infect. Dis. https://doi.org/10.1093/infdis/jiaa523 (2020).

152. The Lancet. Genomic sequencing in pandemics. Lancet 397, 445 (2021)

153. COVID-19 Genomics UK (COG-UK) consortiumcontact@ cogconsortium.uk. An integrated national scale SARS$\mathrm{CoV}-2$ genomic surveillance network. Lancet Microbe 1, e99-e100 (2020).

154. Inzaule, S. C., Tessema, S. K., Kebede, Y. \& Ouma, A. E. O. Genomic-informed pathogen surveillance in Africa: opportunities and challenges. Lancet Infect. Dis. https://doi.org/10.1016/S14733099(20)30939-7 (2021).

155. Jordan, M. I. \& Mitchell, T. M. Machine learning: trends, perspectives, and prospects. Science 349 255-260 (2015)

156. Holmes, E. C. What can we predict about viral evolution and emergence? Curr. Opin. Virol. 3, 180-184 (2013).

157. Carlson, C. J. From PREDICT to prevention, one pandemic later. Lancet Microbe 1, e6-e7 (2020).

\section{Acknowledgements}

R.E.B. is supported by the Cooperative Institute for Modelling

Earth Systems. R.E.B., C.J.E.M. and F.R. are supported by the
High Meadows Environmental Institute at Princeton University. A.W is supported by the US National Institutes of Health through the National Library of Medicine (DP2LM013102) and the National Institute of Allergy and Infectious Diseases (1R01A1160780-01) and a Career Award at the Scientific Interface from the Burroughs Wellcome Fund. Research in the L.-F.W. group is supported by grants from the Singapore National Research Foundation (NRF2012NRFCRP001-056 and NRF2016NRF-NSFC002-013), the National Medical Research Council of Singapore (MOH-OFIRG19MAY-0011, COVID19RF-003 and NMRC/ BNIG/2040/2015) and the Ministry of Education, Singapore (MOE2019-T2-2-130). A.J.T. is supported by the Bill \& Melinda Gates Foundation (INV-024911). S.T. is supported by the Schmidt Science Fellows programme, in partnership with the Rhodes Trust.

\section{Author contributions}

R.E.B., B.L.R. and A.J.T. researched data for the article. All authors contributed substantially to discussion of the content, wrote the article and edited and reviewed the manuscript before submission.

\section{Competing interests}

The authors declare no competing interests.

\section{Peer review information}

Nature Reviews Microbiology thanks Matthew Baylis and the other, anonymous, reviewer(s) for their contribution to the peer review of this work.

\section{Publisher's note}

Springer Nature remains neutral with regard to jurisdictional claims in published maps and institutional affiliations.

\section{RELATED LINKS}

NASA Socioeconomic Data and Applications Center:

https://sedac.ciesin.columbia.edu/

Our World in Data: https://ourworldindata.org/

World Bank: https://data.worldbank.org/

WorldClim: https://www.worldclim.org/

World Health Organization: https://www.who.int/

WorldPop: https://www.worldpop.org/

(C) Springer Nature Limited 2021 